wurden, stört sie die Reaction mit Silberlösung in keiner Weise, da die überschüssige Salpetersäure in letzterer eine derartige Abscheidung unmöglich macht, ebensowenig würde mitübergerissene Salzsäure hindernd eintreten, da diese sofort sichtbar als Chlorsilber abgeschieden wird. Endlich wird aber weit weniger von Zink verbraucht und ebenso von Säure, wodurch die Bestimmung abermals an Genauigkeit gewinnt, der Verbrauch der Säure ist allerdings meist von der zu behandelnden Farbe abhängig. Man könnte beispielsweise sofort die ganze Menge der zur Lösung verwendeten Salz - oder Schwefelsäure in ein Entwickelungsgefäss geben, wenige Stückchen Zink zufügen und nun das Gas durch die am betreffenden Orte beschriebene Silberlösung streichen lassen. Fast übereinstimmend in Farbe und Art des Arsenspiegels tritt bei Spuren ron Arsen eine spiegelnde Ablagerung von Silber an der Einnündung der Gasleitungsröhre in die erste Silberlösung auf, aber Mengen von $1 / 10$ Millig. $\mathrm{As}^{2} \mathrm{O}^{3}$ geben schon reichliche Abscheidung und $0,001 \mathrm{~g}$. und weniger kömnen sehr leicht durch Brom oxydirt und als Magnesiumpyroarseniat bestimmt werden.

Diese Art qualitative und quantitative Bestimmung des Arsen macht die Ausdrücke stark arsenhaltig u. s. w. völlig überflüssig; man kann jetzt mit grösster Genauigkeit auch kleinste Mengen Arsen der Menge nach ermitteln und in Zahlenwerthen vorführen, ohne jede grössere Mühe; im Weiteren verweise ich auf meine Veröffentlichung in dieser Zeitschrift 1880. Bd. 217. S. 1.

Für die Aufklärung des Vorkommens des Arsens in den Farben und die Art der Bindung desselben sind noch zahlreiche Untersuchungen nothwendig und ein reiches Feld dankbarer und wichtiger Arbeiten ist auch hier dem Suchenden geboten.

\title{
Ueber Cinchocerotin.
}

Von A. Helms aus Horsens in Dänemark.

Mittheilung aus dem pharmaceutischen Institute der Universität Strassburg.

Unter dem Namen Cinchocerotin hatte Kerner 1859 und 1862 bei den Weltausstellungen in Paris und London einen von ihm aufgefundenen Bestandtheil der Chinarinden vorgeführt. Die Probe 
desselben, welche mir Herr Prof. Flückiger zur Untersuchung übergab, war in der Zimmer'schen Chininfabrik in Frankfurt a/M. gewonnen und demselben durch Herm Dr. Kerner gütigst überlassen worden.

Ueber die Darstellung des Cinchocerotins theilte der Letztere Folgendes mit:

„Flache südamerikanische Calisayarinde wurde mit Kalkmilch getrocknet, mit Alkohol ausgekocht und abgekühlt. Die Abkühlung erfolgte in kupfernen Röhren, durch welche die Auflösung langsam geführt wurde. Nach 6 bis 9 Monaten waren dieselben mit dem rohen Cinchocerotin incrustirt."

Das rohe Cinchocerotin ist eine braune Masse, aus welcher zwei verschiedene Bestandtheile dargestellt werden können, nämlich ein in Alkohol leicht löslicher, krystallinischer, weisser Körper und in weit geringerer Menge, eine in Alkohol schwer lösliche, weissgelbe Substanz.

Die letztere löst sich gleichfalls schwer in Aether, Chloroform, Benzol und leicht flüchtigem Petroleum, löst sich dagegen leichter in kochendem Amylalkohol und Xylol, aus welchen Lösungen sie sich beim Erkalten amorph ausscheidet. Sie wird bei $230^{\circ}$ zersetzt, ohne zu schmelzen und bildet beim Erhitzen mit Eisessig eine in Alkohol, Aether und Petroleum (60 Siedepunkt) leicht lösliche, weisse, krystallinische Säure, welche bei $\mathbf{5 4}^{0}$ schmilzt. Diese Säure bildet schwerlösliche Baryt-, Blei- und Kalksalze, lösliche Alkalisalze. Weitere Versuche konnten damit nicht angestellt werden, weil das Material nur in kleinen Mengen vorhanden war, und das Cinchocerotin überhaupt bei dem jetzigen Fabrikbetriebe nicht mehr erhalten wird.

Die zuerst erwähnte krystallisirende Substanz, welcher der Name Cinchocerotin verbleiben mag, bildet weisse, sehr leichte, krystallinische Schuppen, die, auf Platinblech erhitzt, ohne besonders auffallenden Geruch verbrennen.

Der Schmelzpunkt liegt bei $130^{\circ}$. Stärker erhitzt sublimirt es theilweise unter Zersetzung. Erhitzt man das Cinchocerotin jedoch im Kohlensäurestrome vorsichtig, so sublimirt es unzersetzt.

Es löst sich leicht in Aether, Chloroform und Alkohol, löst sich nicht beim Kochen mit Wasser, Salzsäure, verdünnter Schwefelsäure und Eisessig. Beim Kochen mit einer Lösung von kohlensaurem. Natrium oder mit Natronlauge wird es nicht angegriffen, auch nicht 
von alkoholischem Natron. Mit concentrirter Schwefelsäure gibt das Cinchocerotin eine rothbraune Lösung.

Es wird von Salpetersäure beim Erwärmen angegriffen, indem sich ein unter $100^{\circ}$ schmelzender, gelber, harzähnlicher Körper ausscheidet. In rauchender Salpetersäure löst sich das Cinchocerotin und wird durch Zusatz von Wasser wieder niedergeschlagen. Der ausgefällte gelbe Körper löst sich in einer heissen Lösung von Natriumcarbonat und wird durch Säure wieder grösstentheils ausgefällt. Der Niederschlag ist gelb, enthält Stickstoff, löst sich leicht in Alkohol, Aether und Chloroform, krystallisirt aber aus diesen Lösungen nicht.

Das Cinchocerotin wird, in Chloroform gelöst, von Brom angegriffen. Es bildet sich ein bromhaltiger, brauner, schmieriger Körper, der sich in Alkohol und Aether löst, aus diesen Lösungen aber nicht krystallisirt.

Mit Essigsäureanhydrid gekocht, löst sich das Cinchocerotin und scheidet sich beim Erkalten wieder unverändert aus.

Mit Essigsäureanhydrid und wasserfreiem Natriumacetat 4 Stunden in einem geschlossenen Rohre auf $150^{\circ}$ erhitzt, verändert es sich nur sehr wenig. Das muthmaassliche Reactionsproduct wurde mit Wasser ausgeschieden, ausgewaschen, in Alkohol gelöst und krystallisirt. Die vier ersten Fractionen waren weiss, der Schmelzpunkt lag zwischen 128 und $130^{\circ}$. Die Mutterlauge war gelb und hinterliess nach dem Verdunsten eine kleine Menge einer gelben schmierigen Substanz. Die weissen Krystalle wurden mit Magnesia gekocht, das Filtrat enthielt kein Magnesiumacetat. Das Cinchocerotin war also fast völlig unverändert und nicht acetylirt.

Mit schmelzendem Kalihydrat wird das Cinchocerotin gelb, mischt sich aber nicht damit. Stärker erhitzt verdampft es theilweise unter Zersetzung. Wird die gelbe Schmelze in Wasser gelöst und mit Schwefelsäure neutralisirt, so bleibt die Flüssigkeit klar; die Lösung ist schwach gelb. Mit Aether geschüttelt wird sie farblos, indem der Aether die Farbe aufnimmt. Nach dem freiwilligen Verdunsten des Aethers schied sich eine sehr kleine Menge gelber Krystalle aus. Diese gaben mit einer verdünnten Lösung von Eisenchlorid eine schwach violette Färbung. Hiernach ist anzunehmen, dass sich eine Spur eines aromatischen Zersetzungsproductes gebildet habe. 
Die Verbrennug des Cinchocerotins gab folgende Resultate:

1.

$$
\begin{array}{lr}
\mathrm{C} & \mathbf{8 0 , 1 5} \\
\mathrm{H} & \mathbf{1 1 , 9 0} \\
\mathrm{O} & \mathbf{7 , 9 5}
\end{array}
$$

2.

$$
\begin{gathered}
79,99 \% . \\
12,17 \text { - } \\
7,84 \text { - }
\end{gathered}
$$

Berechnet für die Formel $\mathrm{C}^{27} \mathrm{H}^{48} \mathrm{O}^{2}$ :

$\begin{array}{cc}\mathrm{C} & 80,20 \% . \\ \mathrm{H} & 11,88- \\ \mathrm{O} & 7,92-\end{array}$

Als die Substanz mit chromsaurem Kalium und Schwefelsäure gemischt wurde, trat sofort eine starke Einwirkung ein. Das Gemisch wurde zwei Tage am Rückflusskühler gekocht; es bildete sich eine grüne Flüssigkeit und ein grüner Niederschlag. Die Flüssigkeit wurde abfiltrirt und der Destillation unterworfen. Das Destillat reagirte sauer und hatte einen deutlichen Geruch nach flüchtigen fetten Säuren, von welchen auch Essigsäure und Buttersäure nachgewiesen wurden.

Der grüne Niederschlag gab mit Natronlauge eine gelbe Lösung und einen Rückstand von Chromoxyd. Die erstere lieferte nach dem Ansäuern einen gelblichen Niederschlag, welcher, ausgewaschen und in Alkohol gelöst, sauer reagirte. Beim Verdunsten der Lösung bildeten sich kleine warzenförmige Krystalle, welche als Cinchocerotinsäure bezeichnet werden mögen. Nach zweimaliger Umkrystallisation schmolzen dieselben bei $72^{\circ}$. Die Verbrennung ergab folgende Zahlen:

Gefunden.

$$
\begin{array}{ll}
\mathrm{C} & 68,75 \% \\
\mathrm{H} & 12,84- \\
\mathrm{O} & 18,41-
\end{array}
$$

Berechnet für die Formel $\mathrm{C}^{10} \mathrm{H}^{22} \mathrm{O}^{2}$ :

$$
\begin{array}{ll}
\mathrm{C} & 68,96 \% . \\
\mathrm{H} & 12,64- \\
\mathrm{O} & 18,39-
\end{array}
$$

Die Säure, mit Natronlauge genau neutralisirt, lieferte mit Bleiacetat und Calciumacetat amorphe Niederschläge. Der Calciumniederschlag, welcher nur aus einer nicht völlig reinen, etwas gelblichen Säure dargestellt werden konnte, da das Material nicht weiter 
reichte, gab 10,76\% CaO. Das Salz wird danach vielleicht als $\mathrm{C}^{28} \mathrm{H}^{64} \mathrm{O}_{\mathrm{COO}}^{2} \mathrm{COO}>\mathrm{Ca}$ aufzufassen sein.

Aus den obigen Resultaten geht hervor, dass das Cinchocerotin kein Wachs oder Fett ist. Es besitzt jedenfalls ein sehr hohes Moleculargewicht, wie man aus dem Verhalten der Cinchocerotinsäure schliessen kann, so dass wohl die einfache Formel $\mathrm{C}^{97} \mathrm{H}^{48} \mathrm{O}^{2}$ kaum der Moleculargrösse des Cinchocerotins entsprechen dürfte. Seinen Eigenschaften und seinem Vorkommen nach zu schliessen, gehört es wahrscheinlich in die Nähe des Betulins und Cerins.

Zuletzt fühle ich mich verpflichtet, Herrn Professor Flückigè für die Freundlichkeit zu danken, mit welcher er mich bei Ausführung dieser Untersuchung unterstützt hat.

\section{Ueber Carvol.}

Von A. Beyer aus Copenhagen.

Mittheilung aus dem pharmaceutischen Institut der Universität Strassburg.

Wir kennen bis jetzt nur drei Pflanzen, welche Carvol enthalten: diejenige des Kümmels, den Dill und die Krauseminze.

Aus Gladstone's Untersuchungen ${ }^{1}$ hatte sich ergeben, dass die physikalischen, hauptsächlich die optischen Eigenschaften des Dillcarvols mit denen des Kümmelcarvols beinahe übereinstimmen. Ferner zeigte Prof. Flückiger, ${ }^{2}$ dass das Carvol des Oeles von Mentha crispa, der deutschen Krauseminze, die Polarisationsebene des Lichtes nach links ablenkt und zwar vermuthlich eben so stark, wie das in entgegengesetztem Sinne drehende Kümmelcarvol, da Gladstone für das Carvol von Mentha viridis eine ähnliche Beobachtung gemacht hatte. Es schien deshalb nicht überflüssig, die drei Carvole nochmals sorgfältig in optischer Hinsicht zu vergleichen.

Da die Schwefelwasserstoffverbindungen derselben bisher nicht optisch geprüft waren, so wurden diese ebenfalls mit in das Bereich der Untersuchung gezogen. Zugleich seien einige Versuche mitgetheilt, welche angestellt wurden, um die völlige chemische Iden-

1) Journal of the chemical. Soc.X. (1872) 1.

2) Berichte d. Deutschen chem. Gesellsch. 1876. 468. 